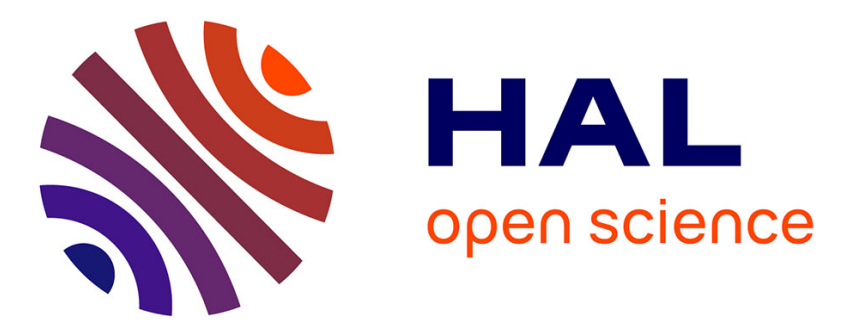

\title{
Knowledge management in a French research community: a case study of GeCSO congress
}

Claude Paraponaris, Jean-Louis Ermine, Claude Guittard, Pascal Lièvre

\section{To cite this version:}

Claude Paraponaris, Jean-Louis Ermine, Claude Guittard, Pascal Lièvre. Knowledge management in a French research community: a case study of GeCSO congress. Vine -London-, 2012, 42 (3/4), pp.302-320. 10.1108/03055721211267459 . hal-01119721

\section{HAL Id: hal-01119721 \\ https://hal.science/hal-01119721}

Submitted on 24 Feb 2015

HAL is a multi-disciplinary open access archive for the deposit and dissemination of scientific research documents, whether they are published or not. The documents may come from teaching and research institutions in France or abroad, or from public or private research centers.
L'archive ouverte pluridisciplinaire HAL, est destinée au dépôt et à la diffusion de documents scientifiques de niveau recherche, publiés ou non, émanant des établissements d'enseignement et de recherche français ou étrangers, des laboratoires publics ou privés.

\section{다)(1) $(5$}

Distributed under a Creative Commons Attribution - NonCommercial| 4.0 International 


\title{
The journal of information and knowledge management systems
}

Volume 42, issue 3/4 - Published: November 2012

\author{
Knowledge Management in a French Research Community: \\ A Case Study of GeCSO Congress
}

\author{
Claude Paraponaris \\ UNIVERSITE PARIS-EST, IRG \\ JEAN-LOUIS ERMINE \\ UNIVERSITE PARIS SUD, MINES-TELECOM \\ Claude GuitTARD \\ UNIVERSITE DE STRASBOURG, BETA \\ PASCAL LIEVRE \\ UNIVERSITE DE CLERMONT, CRCGM
}

\section{Structured Abstract}

Purpose: To present the state of the art of a rising French research community on Knowledge Management, who organized during the past four years years now, a French speaking congress (GeCSO). Interests in Knowledge Management (KM) come from various disciplines; economy, social, engineering. These interests are not often linked. Within the firms, KM practices vary a lot depending on national cultures and on activity sectors. However, one can identify a potential symmetry between the diversity of practices and the partitioning of scientific approaches.

Design/methodology/approach: In order to synthesize the different approaches in KM, we have studied all the 62 papers published in the first three conferences. To have a first representation of the diversity, we analyzed the keywords that were used: among 173 keywords used by the authors, 8 keywords represent $27 \%$ of the total amount.

Findings: We analyze three main dimensions which emerged from the articles: the practical dimension, the epistemological point of view, and the intention to define a theory of action.

Research limitations/implications: The French research KM community is growing, but it is not unique. The work presented only reflects a snapshot of the knowledge capital of this specific research community.

Practical implications: We can give two converging main streams: Knowledge cannot be conceived as objects relevant to physical or economical manipulations. Two KM strategies can be adopted by the organizations. The first one is a defensive strategy to prevent risk. The second one is an offensive strategy, where knowledge is a resource giving the opportunity to develop new products and improve the processes in the firm.

Social implications: Highlight some of the recent research work and themes conducted in the field of Knowledge Management in French speaking countries. We also present the challenge to integrate more and more the different scientific domains of Knowledge Management in the GeCSO community.

Originality/Value: KM is an emerging domain, especially in the French culture. This paper can be seen as a first foundation of the domain, and also a manifesto to develop interdisciplinary research on this topic.

Keywords:

Knowledge management, knowing communities, knowledge transfer, business modeling, situated learning, knowing in action, tacit knowledge, activity theory-based approach, knowledge modeling, knowledge engineering.

Article Classification: Literature review

\section{Introduction}


Interests in Knowledge Management (KM) come from various disciplines; economy, social, engineering. These interests are not often linked. Within the firms, KM practices vary a lot depending on national cultures and on activity sectors. This is one of the missions of the scientific community to indentify these interests, to analyze the potentialities, and to propose an evolution of concepts and practices. However, one can identify a potential symmetry between the diversity of practices and the partitioning of scientific approaches.

In an integrated way, we will present in this article a state of the art of a set of research developed in the French speaking world during the past four years. Although they come from different perspectives, some French speaking researchers have decided to exchange and compare their problematic and methodologies. Since 2008, an annual congress (GeCSO, Gestion des Connaissances: Société et Organisation), creates an opportunity to consolidate exchanges. In this article, we show the common bases of the different fields, as well as their complementarities.

\section{The GeCSO Congress}

The GeCSO congress started with the objective of establishing a dialogue between the different approaches dealing with dynamics of knowledge in the society and in the firms. The originality of the congress is, from one side, the rich interaction between different disciplines and, on the other side, the importance of the relation with practice, as nearly all the presented researches are based on practical experiences.

This dialogue has been going on for four years ${ }^{1}$ without favoring a specific discipline. The constant increase of the number of participants leads to the conclusion that a community is emerging in the French speaking world: it gathers researchers coming from psychology, computer science, economy, management, sociology, communication, learning sciences, and cognitive science.

The different events have gathered researchers from about thirty institutions and from six countries. They have also gathered case studies presented by firms in special sessions ${ }^{2}$. This kind of special sessions gives the opportunity to compare experiences in modeling and managing knowledge and concepts, methods and researches in a more academic framework.

We first present the methodology used to structure this synthesis, and then we will develop each research track including the different studies.

\section{Methodology}

In order to synthesize the different approaches in KM, we have studied all the 62 papers published in the first three conferences. To have a first representation of the diversity, we analyzed the keywords that were used: among 173 keywords used by the authors, 8 keywords represent $27 \%$ of the total amount. They are, by decreasing order:

- Knowledge Management

- Knowledge

- Community

- Modeling

- Sharing

- Innovation

- «Savoir» (in French, another concept for knowledge).

- Engineering

Several dimensions emerged from the articles: the practical dimension, the epistemological point of view, and the intention to define a theory of action.

\footnotetext{
1 - Groupe ESC Troyes (2008), Ecole de Management de Bordeaux (2009), Beta and Ecole de Management de Strasbourg (2010), Centre de Recherche Clermontois en Gestion et Management, Groupe ESC, Clermont-Ferrand (2011). The next edition 2012 will take place in Ecole Supérieure de Gestion, UQAM, Montréal

2 - The presentations in special sessions are not included in this analysis.
} 
The practical dimension can be seen in cases studies in technical or economical environments that are rapidly changing: it may concern questions related to knowledge identification, modeling or sharing. The technological component is important, and the problematic is either to use concepts and methods to achieve a real life specific objective, or to study how knowledge creation and sharing operate, or to build a specific tool. In this dimension, there is a real convergence of the disciplines: social sciences, cognitive sciences or engineering. Most of the papers describe the functioning or the success of knowledge systems.

The epistemological point of view is characterized by the deep precision given to key concepts and terms in analyzing and modeling. It seems mandatory to give definitions linked to knowledge. The authors stress on the importance of giving their own approach on the different cognitive aspects of knowledge, the subjectivity of the notion, and the different modes of expression.

Regarding the theory of action, studying the knowledge dynamics is often adopting an anthropological approach to analyze the link between the subject and his/her environment. Some research is dealing with the link to procedures or techniques; other research is interested by the link to power or economical efficiency. Then, knowledge is linked to individuals together with the groups they constitute, the decisions they take, within socialization processes that are always specific.

This state of the art is not a statistical study. It is based on theories and methods used, explicitly or not, in the different researches described in the articles. This first synthesis is not limited to the different authors, their disciplines and their results. It is oriented towards the underlying concepts of the articles. Concurrently with the progress of analyzing the papers, approaches and concepts were discovered, as numerous mark-ups to explain KM processes.

The identification of the different fields was conducted through a progressive reading, and by referencing the presented concepts and theories. As a matter of fact, for each article, in a systematic way, we have searched for the theories, concepts and methods (and their authors) that are at the heart of the prerequisites of the authors. Each of the 62 articles was part of one to three different fields. We used a saturation methodology to stabilize each and to operate differentiations.

The different researches are grouped in six main fields:

- Knowledge generation from activities

- Epistemological foundations of knowledge as situated action

- Knowledge as situated action

- Knowledge capitalization

- Knowledge modeling, with and around the MASK method

- Epistemic communities, and communities of practice

\section{Knowledge generation from activities}

Activities, as any complex system (organizational system, or informational device) are "knowledge intensive". From that observation, that is mostly shared by management sciences, and knowledge engineering, one need to have pertinent analysis to identify, in the activities, the knowledge creation and dissemination processes, and then build methodologies to facilitate these processes.

Creativity in the activities, especially in design, is also linked to the dissemination of strategic knowledge within the concerned organization. Then, we are within the organization, and we deal with its routines. We highlight the spaces to create and share knowledge in an abductive approach.

\subsection{KM in design activities}

The question is to adapt different time scales in the organization, one for activities or projects, and one for knowledge capitalization.

An example is given in the Myriade project, with a design model based on contradictions (microsatellites design), in CNES (French National Center for Space Studies) studied in Belleval and al., (2010). This program implies for the actors an evolution of their theories of action in the sense of 
Argyris and Schön (1978). The point is to transform a representation based on «Mission Success First » (that targets reliability and robustness of systems) into a representation « Smaller, Faster, Better, Cheaper » inspired by the NASA policy implemented by Dan Goldin, in the early 90 . This evolution is central to the design process.

In that case, the design problem is ill-defined and contradictions may appear during the process. The need is to overcome that problem, and not to stay in the «problem solving » model initiated by Simon (1972). Different theories of design are then mobilized, highlighting the interdependency between three spaces (Pimmler \& Epinger, 1994):

- $\quad$ The space of product (what to do?)

- The space of the design project (how to do?)

- The space of actors (who does what?)

Interaction between problem solving activities and the design process organization has an impact on the number of iterations in the design process, and on the performance (cost, quality, time). Accepting perturbations occurring between these three spaces, we have a new definition of innovative design. Its process is non-structured, because its objective is built following the pace of the activities. The problem to solve is contradictory: a set of technical, organizational or cognitive contradictions has to be cleared (Belleval and Lerch, 2010).

System engineering is a good candidate for such an approach, especially the classical "V life-cycle" of Forsberg and Mooz (1991). This model allows the co-evolution of the problem together with the solution

Requirement analysis leads to define precisely the technical specification that can be discovered as contradictory. These contradictions have to be solved during the architecture design. For that, one can use an existing knowledge base, or give up the project because it is not feasible, or use the contradictions to create new combinations (Altshuler, 1984), by expanding the solutions space (Le Masson and al., 2006).

In each case, one considers the interactions between the technical characterization of the product, the organization of the design project, and the organization of the company, especially the actors. These three dimensions are deployed in different $\mathrm{V}$ cycles to structure design building blocks. The design space is then an open space, with opportunity to solve problems or contradictions by expanding the cognitive, technical and organizational dimensions.

This study shows that a dead end at only one contradiction can cause the project failure (an incremental innovation instead of a disruptive innovation).

\subsection{Towards a generalized approach}

Mastering of interactions between those three dimensions is then strategic for orienting the design project. This leads to an attempt to generalize what is knowledge generation from activities. This is the proposal of the "Bordeaux School" (Brunel, Girard, Moradi, Vallespir, Zolghadri, 2008, 2010) which is a systemic approach that defines an "ingenition" cycle. Those researchers are inspired by the engineering method, and consider that different complementary theories are not linked: design, knowledge and learning. After several actions in industrial domains, they conclude that it is false to think that "good" specialists know how to manage their knowledge and the way they learn. Their goal is to manage the produced knowledge in the design project by taking in account the whole knowledge value chain in a specific organization. For that purpose, a filter "object-semantics-social and structure » is given to design step by step a product together with the appropriate data, then information and then knowledge. All along that value chain, knowledge, competencies and actors are shared. The objective is to build knowledge bases available when designing and developing a product.

The integrating knowledge process has five phases:

- Modeling the context

- Designing the product usage by the client

- Knowledge generation during the extended life cycle of the product

- Comparative scale of internal and external resources 
- Value chain-value sequence-knowledge generation

This process facilitates integration of resources and cognitive capabilities of the firm.

\section{Epistemological foundations of knowledge as "knowing in action" and impact on Knowledge Management}

Specific research is concerned with Knowledge Management from a point of view of epistemology of practice. It concerns the definition of knowledge as a situated practice, as "knowing in action" in the sense initiated in the 50s by Polanyi.

We can distinguish three types of research:

- The research initiated by Lièvre and al. (Lièvre and Rix-Lièvre, 2008, 2010), in the field of "organization studies" intends to give a more theoretical and precise meaning for the notion of tacit knowledge. They prefer to talk about "Knowledge in action", in a sense given by Piaget, and consider that "tacitness" is a characteristic of knowledge in action, and prefer to use "implicit" for that non-explicit aspect. This concerns only individual knowledge. They propose to restrict the tacit dimension of knowledge to a characteristic of collective knowledge, as in law one refers to something that is not yet elicited, but already known by different people. This research is to use the Polanyi's intuition, the Piaget's concepts about "succeed and understand" in the 70s, and the methodological works of Pierre Vermersch, in a psycho-phenomenological perspective, in the 90s to clarify the notions of tacit and explicit knowledge that are central to Knowledge Management. The basic idea is to consider that practices and then attached knowledge are in a pre-reflective state, then non conscious, that operates a fundamental distinction between acting and consciousness of acting. When I read, I read. I don't need to be conscious of reading to read. But I can consciously analyze the way I read to progress. The actor is not able to refer spontaneously to his knowledge, because he rationalizes. He makes his personal experience coherent with his counterpart and his identity. One needs then a specific way to access to theses "knowledge in action", elicitation interview (Vermersch, 1996), self-confrontation interview (Theureau, 1992), subjective re-situ interview (Lièvre-Rix, Lièvre, 2008). It is impossible to access to that type of knowledge by a classical simple sociological interview after the action. These authors propose to study the implications of that theory on Knowledge Management, for instance for knowledge codification.

- The research of Hakim Hachour and Safia Abouad (2008) in information and communication sciences (Paragaphe laboratory, Université Paris 6), in the sociophenomenological framework initiated by Schultz (1953, 1976), distinguishes three types of knowledge: fundamental knowledge, routine knowledge and specific knowledge. (Schutz 1953, 1976; Schutz and Luckman 1973) define three types of knowledge (table 1) and are interested in the cognitive styles for achieving a goal. That process is structured in different steps; the articulations between steps are precisely studied. This approach

(«course-of-action patterns») is developed in Theureau (2006). Tacit or fundamental knowledge is seen as «obvious». This is the result of purely subjective processes. Specific knowledge is separated from action, it is objective. Routine knowledge is attached to practical goals of the action; it is linked to the potential realization included in the daily environment (signification in action).

\begin{tabular}{|l|l|l|}
\hline \multicolumn{1}{|c|}{$\begin{array}{c}\text { Fundamental } \\
\text { Knowledge }\end{array}$} & \multicolumn{1}{c|}{ Routine Knowledge } & \multicolumn{1}{c|}{ Specific Knowledge } \\
\hline $\begin{array}{l}\text { Internalized elements } \\
\text { (capacities) }\end{array}$ & $\begin{array}{l}\text { Elements with growing } \\
\text { specificities }\end{array}$ & Externalized elements (data) \\
\hline Attached to the situation & Dependent on the situation & Independent from the situation \\
\hline Subjective & Inter-subjective & Objective \\
\hline
\end{tabular}




\begin{tabular}{|l|l|l|}
\hline Tacit & Observable - Describable & Explicit \\
\hline Obvious & Incidental & Questionable \\
\hline
\end{tabular}

Table 1: Characteristics of the three types of knowledge, Schutz (1953, 1976).

From these principles, and from analyzing the organization of a socialized knowledge system, those researchers are designing knowledge management systems as a new organization "memory-centered", in a sense given by Lemoigne, which implies three fundamental levels of modeling: the syntactic level (technical), the semantic level (referential), the pragmatic level (implication). These three levels are dependant from a primordial meta-level: ethics.

- The research of Brassac (2008) distinguish two types of studying cognitive processes :

- The "internal" perspective, where cognition is an information processing system operating on cerebral entities and mental states corresponding to real life states that the actor tries to understand, memorize, tell and manipulate

- The "external" perspective that relies brain, body and external world. Cognition is then an activity that doesn't represent the Characteristics of the world, but make them present.

Most of papers analyzed in the present state of the art are in the second perspective, concerning essentially the managers, the routines and the communities. We are then far from the Simon's model of "rationality" (Simon 1972, 1978) and we are more interested in the practices that participate to knowledge elaboration.

\section{Knowledge Transfer}

Knowledge Transfer practices are various and ancient. One can classify them in two parts: the organizational training systems and the specific knowledge transfer systems.

\subsection{Knowledge transfer with training systems}

Wannenmacher (2010) presents a large synthesis of training systems: tutoring, pairing, mentoring etc.

The tutoring function is a process of professional socialization and a process of transmission of professional practices. Tutor is a guide of the new comer and helps him in his learning problems (Boru and Leborgne, 1992).

The pairing function facilitates the new comer's socialization. He is associated to an experimented worker during all his learning period (Meignant, 2001).

The mentoring function disseminates know how, competencies within specific working communities.

These three functions favor interactions. One cannot disseminate know how without simple actions as observation, impregnation, imitation, practical experience, advising by experienced workers, demonstration, trial-and-error, exercises. But to be effective, some conditions for learning must be fulfilled.

\subsection{Knowledge transfer between « Knower » $(K)$ and «Learner » $(L)$}

Research of specific conditions to realize critical knowledge transfer within an organization leads to a better understanding of the knowledge transfer process. Brassac $(2000,2008)$ develops a methodology for supporting knowledge transfer, based on an approach of social psychology of cognitive processes.

The most relevant situations are the retirements of a technician or engineer.

Knowledge acquisition is a process where at least two actors, "Knower" $(\mathrm{K})$ and Learner $(\mathrm{L})$, are coresponsible. This process takes place in a set of social interactions, discursive exchanges, body language, and machines manipulations. The actors must maintain these manipulations. Under those conditions, there is no real knowledge transfer, but a construction of significations that are to be used afterwards by $\mathrm{L}$, after acquisition.

To facilitate that acquisition, Brassac develops the following methodology: 
- Speech collection is not enough

- You should not disconnect the speech of $\mathrm{K}$ and the apprehension of this speech by A,

- You should not abstract the expression of the expertise of the concrete place of effectuation,

- You should not prevent both actors $\mathrm{C}$ and $\mathrm{A}$ from representing diagrammatically working elements

This is the opportunity for $\mathrm{K}$ and $\mathrm{L}$ to have a direct relationship: for knowledge, hesitations, oversights, documents or limits dependencies. This preserves the possibility of asking, raises incoherencies or conflicts, and proposes new perspectives. For that reason, it is necessary to have three persons: K, L and a knowledge engineer (or the researcher). One uses overviews in concrete working context, films, interviews, comments on films.

Transfer possibilities are possible because knowledge is distributed among $\mathrm{K}$ and artifacts (documents, equipments...). A good strategy is to have a constant feed-back with the different ways of collecting knowledge (diversity, redundancy). This is the way to reveal discrepancies between performative statements and experiences, and give recommendations and performative reformulations.

To summarize, two practical recommendations are formulated:

- Retention: organization of the documentation, expertise retention, organization of resources after corpus analysis.

- Capitalization: save operational protocols, anticipate the next transfer and design a back-up for L's activity.

\section{Industrial Knowledge Capitalization}

\subsection{Lessons learned for technical objects}

In an engineering context, working on technical objects, Knowledge Management is useful for the actors to give sense to information on objects, and browse among the different objects they manipulate in their activities. An example is given by TEEXMA (Rachedi and al. 2010) used as a support for lessons learned. In that tool, a situation can be attached as a fact to a technical object, and can be documented with a short piece of knowledge, that can be appropriated by the concerned actors, in an objective of continuous improvement.

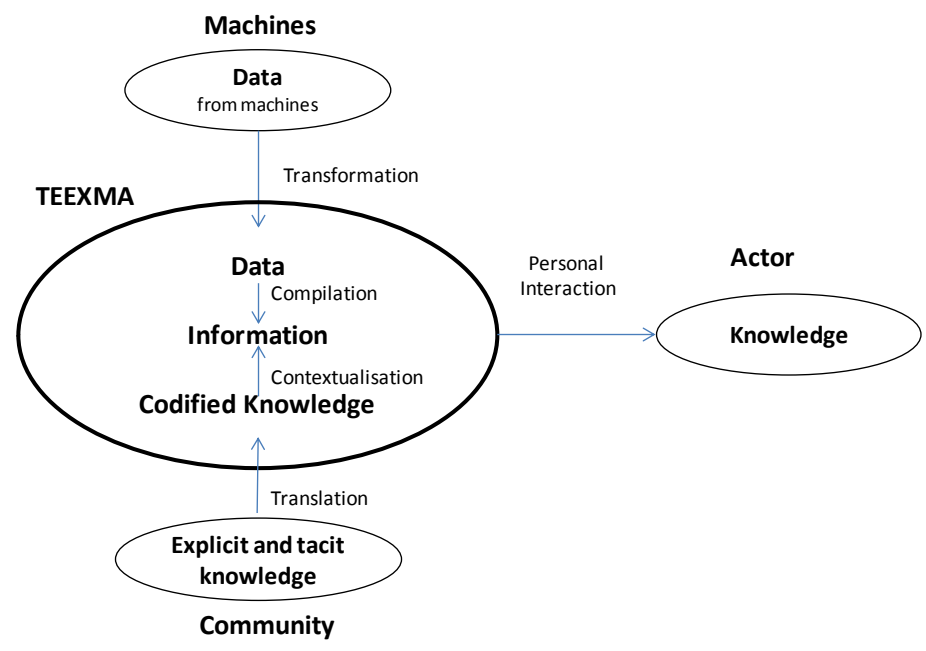

Figure 1: The TEEXMA@ tool for technical Knowledge Management

(Rachedi, Boujut and Poussier , 2010).

\subsection{Capture professional gestures}


Another given example of Knowledge Capitalization technique is given by video-based knowledge capture. This technique is developed in a sensible domain: nuclear energy (EDF, the French Power Supplier), to capture the know-how incorporated in technical gestures called "rare". A very deep research has been made about diversity and quality of video-taping and about elicitation modes by actors during recordings (Le Bellu, Lahlou and Le Blanc, 2009).

The EDF approach is based on a subjective view of the operator's activity, and on a protocol for collecting subjective cognitive elements concerning technical gestures in context. Two cameras are used, one outside the operator, one carried by the operator, nearby his gestures. The choice of « firstperson » filming fosters the identification process to the operator by the observer. It increases also the quality of elicitation by the operator.

The questions are: are the operator's routines unconscious (proportionally to his expertise)? How to make him elicit his routines? What are the limits?

The filming technique is very specific. The operator is mentally prepared, and is asked to think of his gesture, to have a reflexive posture regarding his gesture (tell successively goals and results) in order to give the best possible description, in a format adequate to have a cognitive modeling and then a structure for training documents.

\section{Knowledge Modeling around and with MASK}

A lot of research refer to the MASK method (Method for Analyzing and Structuring Knowledge), developed by Jean-Louis Ermine (1996, 2008), vastly used for industrial use and others ${ }^{3}$.

In the last version, the MASK method has two parts: the first one (MASK II) is a method for identifying an organization's strategic knowledge portfolio (knowledge mapping), the second one (MASK I) is a method for knowledge preservation, based on modeling techniques for tacit knowledge.

\subsection{MASK II : Knowledge Identification with knowledge maps}

\section{Knowledge mapping}

Knowledge mapping is a modeling method to classify knowledge and access to the right knowledge at the right moment. This is a management process to identifying the portfolio of strategic knowledge, and for the design of a KM plan of the organization. Different approaches can be used with different issues for KM (table 2).

\begin{tabular}{|c|l|}
\hline $\begin{array}{c}\text { Functional } \\
\text { classification }\end{array}$ & $\begin{array}{l}\text { It tags the competencies. It is easy to make, and is privileged by the } \\
\text { management. It is based on the organization chart of the company, and then } \\
\text { depends a lot on that organization. } \\
\text { - }\end{array}$ \\
\hline $\begin{array}{c}\text { Knowledge } \\
\text { domains } \\
\text { classification }\end{array}$ & $\begin{array}{l}\text { A knowledge domain is related to the activity of a group of actors. This } \\
\text { approach is adapted when the complexity level is high. The models may be, for } \\
\text { instance, trees or cognitive maps (Ermine 2007). }\end{array}$ \\
\hline $\begin{array}{c}\text { Processes } \\
\text { classification }\end{array}$ & $\begin{array}{l}\text { It links knowledge to activity. It is rather complex to operate. It comprises four } \\
\text { steps: sensible processes and collective consensual issues, critical activities } \\
\text { linked to those processes, knowledge needed to solve the main problems, } \\
\text { measurement of the criticality of this knowledge. }\end{array}$ \\
\hline
\end{tabular}

Table 2: Three types of approach for cognitive resources mapping

\footnotetext{
${ }^{3}$ - See for instance : http://aries.serge.free.fr/
} 


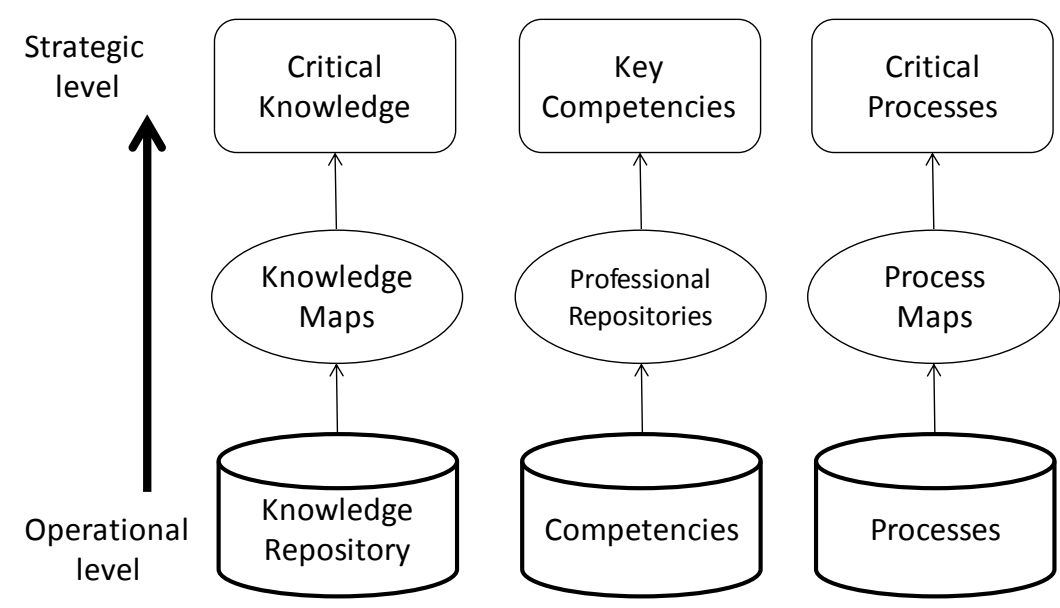

Figure 2: The three approaches knowledge/competencies/processes Aubertin (2007)

The knowledge map may be used as a data repository, and processed by data mining techniques to progressively elaborate knowledge (Menaouer and Baghdad, 2009).

The connection between the knowledge map and the firm's units is essential. The knowledge systems can be maintained through two logics (figure 2). One is from knowledge to action; the other is from the operational level to the strategic level.

\section{Critical knowledge maps}

Knowledge mapping can be extended, in some sensible domains (agriculture, nuclear energy, personal cares, extreme environments...), to minimize the "knowledge crash" risk (i.e. loss of knowledge that can be fatal). According to Grundstein (2002), crucial knowledge are necessary for companies to solve their critical problems. Each knowledge domain is tagged by a criticality measure that is based both on vulnerability of knowledge (rareness, accessibility, cost and delays for acquisition), and its strategic importance.

This analysis is made by semi-directive interviews with institutional and practitioners, in three parts. We give an example for a system in organic farming (Soulignac and al., 2010).

The first part gives the general contexts and infrastructures and identifies where the concerned actors are. The second part develops the informational activities. The third gives a model of information flows between the institutions and others actors. Each type of information is related to the supports (technological dimension), the origin (organizational dimension) and the content (informational dimension) (the SOC model: Support, Origin, Content). Relational matrices are then established to identify flows (information-prescription): weak knowledge flows and strong knowledge flows.

After this phase of identification of the knowledge system involved in organic farming, the map of the different knowledge domains is built, and for each knowledge domain, the criticality is calculated, and domains are classified (figure 3). Criticality is proportional to a combination of four parameters: usefulness, rareness, difficulty of acquisition, difficulty of use. Criticality evaluation is qualitative; it is calculated with a grading system. 


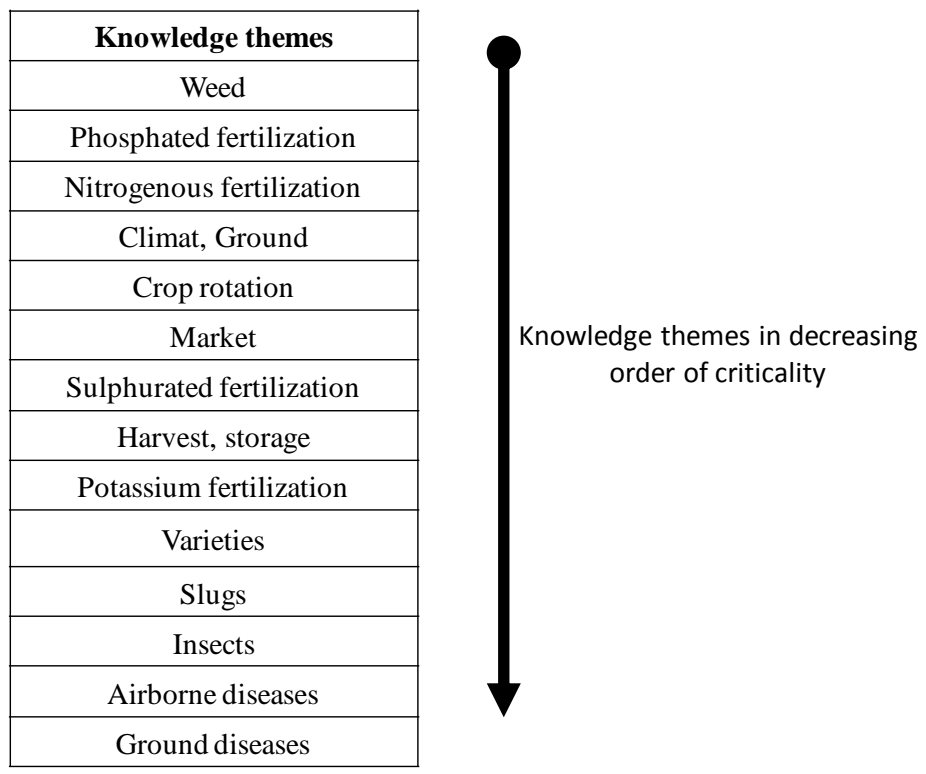

Figure 3: Identifying the critical knowledge in organic farming Soulignac, Ermine, Paris, Devise, Chanet (2010)

Reducing criticality requires knowledge development and acquisition by a significant number of actors. This must be designed according the double nature of knowledge

\subsection{MASK I : Knowledge elicitation with modeling techniques}

MASK I is a Knowledge Engineering method. Its objective is to collect and capitalize tacit knowledge of experts with interview and modeling techniques (Ermine, 2008). The objective is to deliver a structured synthesis of the knowledge on a given domain in a form named (as a metaphor) a « Knowledge Book».

This method is a tool for an expert, in interaction with a knowledge engineer, to analyze and formalize his knowledge to create a knowledge base. It is based on conceptual framework given by the "knowledge macroscope" (figure 4). It is a modeling method based on six different models for six different fundamental types of knowledge (table 3).

In practice, the MASK I method is implemented in three steps:

- Knowledge elicitation: that process consists in making visible an added-value part of a personal or collective tacit knowledge ("pushing away the tacit frontier"). Elicitation is made by interviews with knowledge holders, co-construction of different knowledge models, peer reviews and assessments.

- Knowledge Book, or Knowledge Repository design, structured by the explicit knowledge collected in the first step

- Implementation of It-based Knowledge Systems (Knowledge Servers, Learning Systems, Collaborative Systems for Communities) 


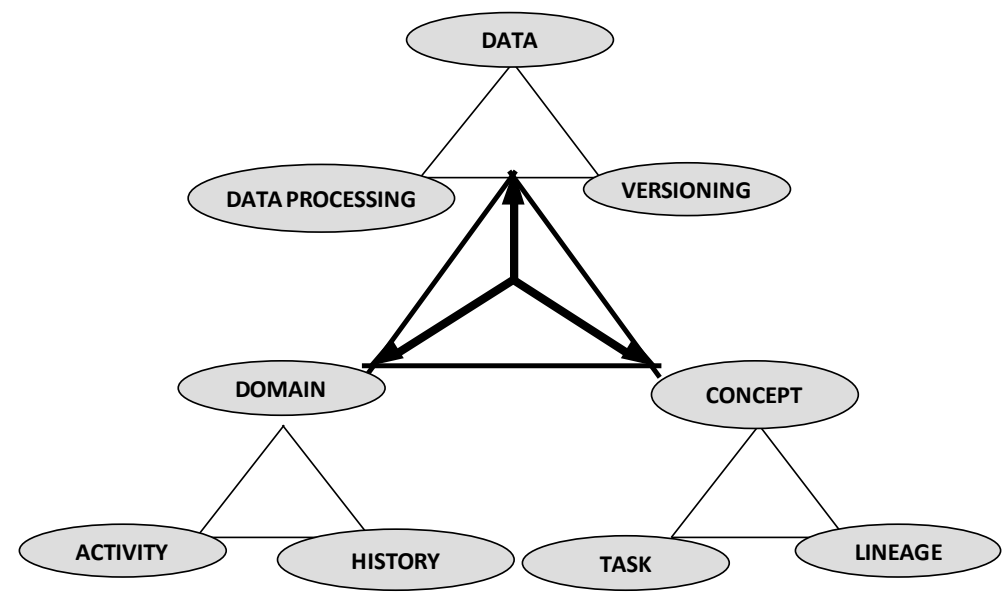

Figure 4: Knowledge Macroscope in MASK I (Ermine, 1996)

The limits of this elicitation process are regularly discussed in the GeCSO congresses (Lièvre and Bonnet, 2010). The transfer of real life situated experience of experts to modeling of this experience with the MASK I models is related to very important questions. How to skip from the expert's practices, which are "unlogic" in the sense given by Bourdieu (1994) to a formal logic framework given by the MASK I models? The basic idea is to start from investigating "knowledge in action" (Piaget), with a methodology as the elicitation interview (Vermersch 1996), and then build a link between the level of "knowledge in action" and the formal level of MASK

Domain: model general phenomena that must be mastered in the domain

Activity: model the processes of the domain. Identify and decompose the activities, the flows between activities, the actors, the resources. Identify the knowledge, know how ...

Concept: model the conceptual structure of an expert (semantic network)

Task: model know how as problem solving methods.

History: model the historical context explaining the evolution of the domain.

Lineage: model genealogic trees of solutions, ideas, products ... with the attached pros and cons.

\section{Table 3: the different models in MASK I}

\section{Epistemic communities and communities of practice}

Specific research on communities is conducted at the Strasbourg school, within the BETA lab (Bootz, Burger-Helmchen, Créplet, Cohendet, Dupouët, Guittard, Kern, Munier, Pénin, Schenk). Its interest is in knowledge dynamics, and its relationship to authority.

\subsection{Different approaches for communities}

Research on communities of practice and on epistemic communities has now a well-known genealogy. The first identification of communities was made in case studies.

Orr (1990) is recognized to be the founder of this research relative to learning, socially designed by the employees. More generally, the literature on community is presented with four main streams, based essentially on North American sociology:

- Learning by practice (Brown and Duguid, 1991)

- The situated characteristic of knowledge (Greeno and Moore, 1993)

- Learning as a social construct (Lave, 1988, 1991)

- Learning as a social practice where significations linked to action are negotiated (Wenger, 1998) 
The relationship between communities and knowledge is that of local and socialization. Communities are analyzed as places where, permanently, local models, shared representations and jargons are built, hence enabling synergies of individual varieties (Amin and Cohendet, 2004). A community is founded on self-made norms that are de facto guides for action. Not to respect the norms may jeopardize the community (Munier, 2009).

Most of organizations are made of several communities. How then can functional organization and autonomous communities be coordinated?

\begin{tabular}{|l|l|}
\hline \multicolumn{1}{|c|}{ Communities of Practice (CoPs) } & \multicolumn{1}{|c|}{ Epistemic Communities (EC) } \\
\hline $\begin{array}{l}\text { Their objective is to improve their activity by } \\
\text { leading a reflection on the practices, building and } \\
\text { sharing a common repository of resources. }\end{array}$ & $\begin{array}{l}\text { Small working groups composed of actors } \\
\text { working on subset of mutually recognized } \\
\text { problems linked to a type of knowledge, which, } \\
\text { at least, accept a procedural authority, recognized } \\
\text { bocialization process made of tacit knowledge, } \\
\text { socially localized in shared repository of } \\
\text { common resources (routines, artifacts, } \\
\text { vocabulary and styles). }\end{array}$ \\
$\begin{array}{l}\text { essential to the success of their cognitive activity } \\
\text { (Cowan, David and Foray, 2000). } \\
\text { They use codebooks: dictionaries, grammar rules, } \\
\text { to facilitate communication and synergies. } \\
\text { They create knowledge with the use of } \\
\text { externalization. }\end{array}$ \\
\hline
\end{tabular}

\section{Table 4: The two types of community}

The study of community implies the study of problematic interactions. Interactions with hierarchical structures ask the question of knowledge dissemination and combination. In that case, communities are not a lot concerned. Interactions between autonomous communities ask the question of knowledge transfer, with the background of organizational pressure.

\subsection{The antinomy Hierarchy-Community}

The rules for the hierarchy and the communities are antagonist. The community can have pressure from the hierarchy in its organization. But the community is creative through its own norms, and more generally through the interactions of its members. The hierarchy is interested in the community to develop its activities, to innovate and to control. From a synchronic point of view, the relationship firm > community can be apprehended as a pressure (Munier, 2009). A community is viable if it respects the social norms elaborated by its members, it acts regarding a repository of norms. Hence, the community can stand the pressure, if and only if, the required norms belong to the repository of possible norms.

If a firm is always objective-driven, a community evolves regarding its past, its action is structured by constraints on its resources and orientation on its rules. The firm, as a regulator, must manage a double bind: respect the norms of the community, and capture and orientate this community. We have then a double governance structure, which justifies the interest of studying the complementarities between "entrepreneur" and "manager" from a management point of view.

From a classical point of view, the community is considered as a risk of losing control. Advanced studies prove now that is not really true. The strange characteristics of a knowledge community must be seen as a managerial innovation, and not as an organizational risk (Bootz and Kern, 2010).

\begin{tabular}{|l|l|}
\hline \multicolumn{1}{|c|}{ Entrepreneur role } & \multicolumn{1}{|c|}{ Manager role } \\
\hline $\begin{array}{l}\text { Oriented towards dissemination and management } \\
\text { of new knowledge, tacit activity, difficult to } \\
\text { identify. }\end{array}$ & $\begin{array}{l}\text { Oriented towards internal/external links. } \\
\text { Guarantee an environment favorable to } \\
\text { community creation, and manage the knowledge } \\
\text { by codification. }\end{array}$ \\
\hline
\end{tabular}


Intention + attention.

Intention: wish to implement a given strategy and rally the company.

Attention: observation and assimilation of weak signals from all communities.

The entrepreneur tries to maintain knowledge diversity together with dialog.
Preoccupied by interfaces management to keep control.

Use of frontier objects to guarantee communication.

Table 5: Entrepreneur and manager roles, Bootz and Kern (2009), Créplet and al., (2001).

From an evolutionist point of view, several ways for promoting communities are explored (Créplet and Dupouët, 2009). The authors recommend to not directly managing the communities, in order to create an efficient environment for communities development, and to not edict contradictory injunctions of rules or norms.

\section{Conclusions}

As a synthesis of this transverse analysis, we can give two converging main streams:

10.1. Knowledge cannot be conceived as objects relevant to physical or economical manipulations

A clear distinction is made between information and knowledge:

- Knowledge is structured in personal schemes and in dialogist processes "person/environment"

- Information is the code used by knowledge to disseminate. It may be the support for knowledge transfer

\subsection{Two Knowledge Management strategies}

Two KM strategies can be adopted by the organizations. The first one is a defensive strategy to prevent risk (knowledge loss, knowledge crash). Knowledge codification is a main tool in that strategy (Knowledge Books, procedures, documentation...). The second one is an offensive strategy, where knowledge is a resource giving the opportunity to develop new products and improve the processes in the firm. There are many tools for that strategy, which can be seen as supports and combinations of two types of knowledge transfer (Figure 5).

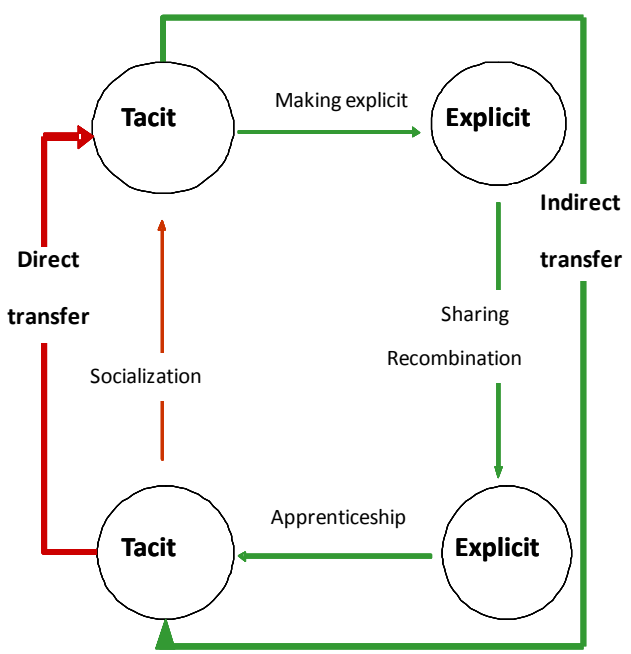

Figure 5: Indirect and direct knowledge transfer, according to Nonaka, Ermine (2007). 
Exploring those two strategies will be, with no doubt, the next challenge to integrate more and more the different scientific domains of Knowledge Management in the GeCSO community.

\section{References}

Amin, A., and Cohendet, P., 2004. The Architecture of Knowledge, Oxford University Press, Oxford.

Argyris C., and Schön D., 1978. Organizational Learning. Addison-Wesley, Reading, MA.

Aubertin, G., 2007). Cartographier les connaissances critiques: une démarche stratégique pour l'entreprise. Management des connaissances en entreprise. Lavoisier. Paris, Hermes Science: Pages 125 à 144.

Belleval, C., Deniaud, I., and Lerch, C., 2010. Modèle de conception à base de réseau de contradictions. Le cas de la conception des microsatellites au CNES, Actes du $3^{\text {ème }}$ Colloque Francophone de Gestion des Connaissances, mai, Université de Strasbourg.

Bootz J.P and Kern F., 2010. Les communautés de connaissance: leviers de changement organisationnel pour le manager et l'entrepreneur, Actes du $3^{\text {ème }}$ Colloque GeCSO Gestion des Connaissances, Université de Strasbourg.

Bootz J.P and Kern F., 2009. Les communautés en pratique : leviers de changements pour l'entrepreneur et le manager, Editions Hermès - Lavoisier.

Boru J.J. and Leborgne C., 1992) Introduire et développer la fonction tutorale dans les entreprises, Actualité de la Formation Permanente, n¹19, p. 24

Bourdieu P., 1994. Raisons pratiques, Editions du Seuil, Paris.

Brassac, C., 2008. L'acquisition de savoirs comme activité située et distribuée, Actes du $1^{\text {er }}$ Colloque GeCSO, ESC Troyes.

Brassac, C., 2000. Intercompréhension et Communiaction ${ }^{\circledR}$, in A.-C. Berthoud, L. Mondada (éds), Modèles du discours en confrontation, Berne, Peter Lang, 219-228.

Brassac C., 2004. Action située et distribuée et analyse du discours : quelques interrogations, Cahiers de Linguistique Française, 26, 251-268.

Brown J.S., and Duguid P., 1991. Organizational learning and communities-of-practice: Toward a unified view of working, learning and innovation. Organization Science, Vol. 2, n ${ }^{\circ}$ 1, pp. 40-57.

Brown J.S., and Duguid P., 2001. Knowledge and Organization: A Social-Practice Perspective, Organization Science, Vol. 12, $\mathrm{n}^{\circ}$ 2, pp.198-213.

Brunel, S., 2008. Etude des activités collaboratives de conception en tant que situation d'apprentisage : application à l'ingénierie des produits et à l'ingénierie didactique. Thèse $\mathrm{N}^{\circ} 3680$, Bordeaux 1 University, France.

Brunel, S., Zolghadri, M., and Girard, P., 2008. Ingénition: une méthode stratégique pour la génération de la connaissance, Actes du 1er Colloque GeCSO, ESC Troyes.

Choulier, D., 2008. Comprendre l'activité de conception, Collection Chantiers, Université de Technologie de Belfort-Montbéliard.

Cowan, R., David, P., and Foray, D., 2000. The explicit economics of knowledge codification, Industrial and Corporate Change, 9, 2, 211-253.

Créplet, F., Dupouet, O., Kern, F., and Munier, F., 2001. Dualité cognitive et organisationnelle de l'entreprise : le rôle différencié du manager et de l'entrepreneur, Revue d'Économie Industrielle, $\mathrm{n}^{\circ}$ 95, pp. 9-22.

Créplet, F., and Dupouet, O., 2009. Communautés d'apprentissage et pratiques prospectives : de l'aide à la décision au management des connaissances in Bootz J.P and Kern F., Les communautés en pratique : leviers de changements pour l'entrepreneur et le manager, Editions Hermès - Lavoisier. 
Dieng-Kuntz, R., 2007. Capitalisation des connaissances via un web sémantique d'entreprise. Management des connaissances en entreprise. Lavoisier. Paris, Hermes Science, 255-272.

Ermine, J.L., 1996. Les systèmes de connaissances. Editions Hermès.

Ermine, J.L., 2007. Introduction au Knowledge Management in Management des connaissances en entreprise. Lavoisier. Paris, Hermès Science, p. 23-45.

Ermine, J.L., 2008 Management et ingénierie des connaissances, modèles et méthodes, Hermes Science publications, $376 \mathrm{p}$.

Forsberg, K. and Mooz, H.1991. The Relationship of System Engineering to the Project Cycle. INCOSE, pp. 57-65.

Greeno, J.G., and Moore, J.L., 1993. Situativity and symbols : Response to Vera and Simon, Cognitive Science, ${ }^{\circ} 17$, pp. 49-59.

Grundstein, M., 2002. Gameth : un cadre directeur pour repérer les connaissances cruciales pour l'entreprise, Lamsade Université Paris-Dauphine: 18 pages.

Lave J., 1988. Cognition in Practice. Cambridge : Cambridge University Press.

Le Bellu, S., Lahlou, S., and Le Blanc, B., 2009. Comment capter le savoir incorporé dans un geste technique à l'aide d'outils numériques? , Actes du $3^{\text {ème }}$ Colloque GeCSO Gestion des Connaissances, Bordeaux.

Le Boterf, G., 2008. Travailler efficacement en réseau une compétence collective, Eyrolles Editions d'organisation.

LeMasson P., Weil B. and Hatchuel, A., 2006. Les processus d'innovation : conception innovante et croissance des entreprises. Hermès.

Lièvre, P., and Bonnet E., 2010. Retour sur la mise en œuvre de la méthode MASK à la conduite du blé biologique : la question du mode d'investigation des connaissances tacites, Actes du 3ème Colloque GeCSO Gestion des Connaissances, Université de Strasbourg.

Lièvre, P., and Rix-Lièvre, G., 2010. La dimension «tacite » des connaissances expérientielles : une mise en perspective théorique et méthodologique, Actes du $3^{\text {ème }}$ Colloque GeCSO Gestion des Connaissances, Université de Strasbourg.

Meignant A., 2001, « Former sans la formation? », Personnel, n²421, juillet, p. 29.

Menaouer B., Baghdad.A., 2009. Vers une cartographie des connaissances guidée par fouille de données, Actes du 3ème Colloque GeCSO Gestion des Connaissances, Bordeaux.

Munier, F., 2009. Viabilité des communautés de pratique pilotée : un modèle dynamique, Actes du $2^{\text {ème }}$ Colloque GeCSO Gestion des Connaissances, BEM, Bordeaux.

Orr J., 1990. Sharing knowledge, celebrating identity: war stories and community memory in a service culture. Collective remembering, D. S. Middleton and D. Edwards, eds., Sage, Beverly Hills, CA, pp. 169-189.

Piaget J., 1974a. La prise de conscience, PUF, Paris.

Piaget J., 1974b. Réussir et comprendre, PUF, Paris.

Pimmler, T.U. and S.D. Eppinger, 1994. Integration Analysis of Product Decompositions. Proceedings of the ASME Design Theory and Methodology Conference, vol. 68, p. 343-351.

Polanyi, M., 1962. Personal knowledge: towards a post-critical philosophy. New York: Harper Torchbooks.

Rachedi, S., Boujut, J.-F., Poussier, G., 2010. Etude de cas d'une offre industrielle de management des connaissances techniques, Actes du $3^{\text {ème }}$ Colloque GeCSO Gestion des Connaissances, Université de Strasbourg. 
Rix, G., Lièvre, P., 2008. Towards a codification of practical knowledge, Knowledge Management Research \& Practice, 6, 225-232.

Schenk, E., Guittard, C., and Cohendet, P., 2010. TIC et communautés : le forum comme espace de socialisation, Actes du $3{ }^{\text {ème }}$ Colloque GeCSO Gestion des Connaissances, Université de Strasbourg.

Schön, D., 1983. The reflective practitioner. How professional think in action, Basic Books, New York.

Schön, D.A., 1996. The reflective practitioner, How Professionals Think in Action, Ashgate Publishing Limited.

Schutz, A., 1953. Common-sense and Scientific Interpretation of Human Action. In The Problem of Social Reality, Collected Papers I, La Hayes : Martinus Nijhoff, 1962, pp.3-47.

Schutz, A., 1976. The Phenomenology of the Social World [1932]. Londres : HEB.

Schutz, A., and Luckmann, T., 1973, 1989. The Structures of the Life-World (Volume I and II). IL, Evanston : Northwestern University Press.

Simon, H., and Newell, A.,1972. Human problem solving, Prentice Hall, Englewood Cliffs, N.J.

Simon, H., 1978. Rationality as Process and Product of Thought, American Economic Review, Vol. $68, n^{\circ} 2$, pp. 1-16.

Soulignac, V., Ermine, J.L., Paris, J.L., Devise, O., and Chanet, J.P., 2010. Gestion informatisée des connaissances pour une agriculture durable, Actes du $3^{\text {ème }}$ Colloque GeCSO Gestion des Connaissances, Université de Strasbourg.

Theureau, J., 2006. Le cours d'action: méthode développée. Octares, Toulouse.

Vermersch, P., 2003. L'entretien d'explicitation, ESF.

Wannenmacher, D., 2010. Le partage de connaissances tacites : l'importance de l'interaction in situ, Actes du $3^{\text {ème }}$ Colloque GeCSO Gestion des Connaissances, Université de Strasbourg.

Wenger, E., 1998. Communities of practice: learning, meaning and identity. New York: Cambridge University Press. 